\title{
Herpes Simplex Virus Infection Mimicking Bullous Disease in an Immunocompromised Patient
}

\author{
Anne L.Y. Lecluse Carla A.F.M. Bruijnzeel-Koomen \\ Department of Dermatology and Allergology, University Medical Centre Utrecht, \\ Utrecht, The Netherlands
}

\section{Key Words}

Herpes simplex infection - Herpes simplex virus - Immunosuppression - Tzanck test

\begin{abstract}
Immunodeficient patients are at risk of developing extended or atypical herpes simplex virus infections, which can be easily misdiagnosed. We present the case of a 79-year-old, treatment-induced (oral corticosteroid), immunocompromised female with an extensive atypical herpes simplex virus infection. This patient presented with multiple erosions and vesicles on the trunk with a subacute onset. The clinical differential diagnosis was herpes simplex infection, herpes zoster infection, pemphigus vulgaris or bullous pemphigoid. Due to the atypical clinical presentation and negative Tzanck test, suspicion of viral infection was low. High-dose steroid treatment was initiated. Subsequent histopathology, however, showed a herpes simplex virus infection. After discontinuing steroid treatment and initiating antiviral treatment, the patient recovered within a week. Emphasis must be placed on the importance of clinical awareness of extended and clinically atypical herpes simplex infections in immunocompromised patients. A negative Tzanck test does not rule out the possibility of a herpes infection.
\end{abstract}

\section{Introduction}

Herpes simplex virus (HSV), a double-stranded DNA virus, is a common human pathogen, classically causing orofacial (mostly HSV-1) or genital (mostly HSV-2) infections [1]. The clinical presentation ranges from mild uncomplicated mucocutaneous infection to occasionally life-threatening, disseminated infection [2]. The pathogenesis follows the sequence of primary infection, latency in the local dorsal root ganglion of a sensory neuron, and reactivation $[1,2]$. Of all human herpes viruses, HSV-1 infections are the most common. About $90 \%$ of individuals between 20 and 40 years old have been shown to have antibodies against HSV-1 [1]. Primary HSV-1 infections occur mainly in infancy or childhood and are usually mild or subclinical [1]. Later, the virus can be 
reactivated spontaneously or by suppressed immunity, for example by trauma, fever, menstruation, ultraviolet radiation or immunosuppressive medication $[1,2]$.

Latent HSV may be reactivated by primary immunodeficiency or treatment-induced immune suppression. In these patients extensive skin involvement may occur with symptoms like malaise and fever. Atypical infections have been reported more frequently in immunocompromised patients than in immunocompetent hosts [3]. Also, cases of disseminated HSV infections with internal organ involvement (especially hepatitis) have been described in immunocompromised patients [4-7]. Both atypical and extended infections are associated with increased morbidity and mortality.

\section{Case Report}

A 79-year-old woman was referred to our out-patient dermatology department presenting with subacute onset, painful and itching blistering on the back. She was feeling ill, but had no fever. Her medical history mentioned an urothelial carcinoma which was treated by nephro-ureterectomy with lymph node dissection and adjuvant radiotherapy. Rectal blood loss due to mucosal radiation damage was treated by oral prednisone ( $20 \mathrm{mg}$ daily) maintenance therapy. Furthermore, her medical history mentioned atrial fibrillation, hypertension, depression, and arthrosis. Her medication listed carbasalate calcium, amiodarone, citalopram, domperidone, esomeprazole, fentanyl, ferrofumarate, furosemide, lactulose, lorazepam, nadroparin, oxycodone, paracetamol, and spironolactone. History of previous orofacial herpes infections was unknown.

Clinically, multiple eroded vesicles and blisters with minimal surrounding erythema were seen on the back. The lesions were located mostly on the left side of the back within a disseminated distribution (fig. 1). Two crusted erosions were present on the thorax and nose; the oral mucosa was not affected. The clinical differential diagnosis was herpes simplex infection, herpes zoster infection, pemphigus vulgaris or bullous pemphigoid. Tzanck test, taken from the base of a vesicle, was negative. The clinical working diagnosis was autoimmune blistering disorder due to the atypical distribution of the skin lesions and negative Tzanck test. The patient was treated with oral prednisone $(1 \mathrm{mg} / \mathrm{kg} / \mathrm{day})$ and class IV topical corticosteroids.

Two days later, histopathology showed intra-epidermal blistering with multinucleated keratinocytes with ground glass nuclei and acantholysis. Immunohistochemistry with polyclonal antibodies against HSV-1 and HSV-2 was positive. Immunofluorescence was negative for autoimmune blistering disorders. Upon the diagnosis herpes simplex infection, oral and topical steroid treatment was discontinued and oral aciclovir (1,000 $\mathrm{mg} 3$ times daily) and local zinc oxide were initiated. The skin lesions improved within a week.

\section{Discussion}

HSV infections have been reported more often in immunocompromised patients than in immunocompetent hosts [3].Generalized or atypical HSV infections have been described in pregnant women, neonates, with oral corticosteroid immune suppression and immunosuppression after kidney or bone marrow transplantation [8]. These infections usually are a reactivation of a previous HSV infection [3]. Characteristics of atypical infections in immunocompromised patients include: larger size of lesions, deeper ulceration, satellite lesions, longer healing time, HSV shedding in the saliva, and atypical locations [3]. Atypical HSV infections in immunocompromised patients may resemble autoimmune blistering disorders like pemphigus vulgaris, pemphigus foliaceus or bullous pemphigoid. Herpes zoster infection must also be considered in the differential diagnosis. Atypical HSV infections mimicking autoimmune blistering disorders can cause diagnostic delay and delayed or incorrect treatment. 
Although the diagnosis of HSV infections is usually made clinically, Tzanck test, electron microscopy, viral culture and polymerase chain reaction (PCR) detection of HSV DNA can be utilized to verify the diagnosis $[2,9]$. In our case, the atypical clinical presentation and negative Tzanck test discouraged the initial clinical diagnose of a HSV infection, resulting in the initial working diagnosis of autoimmune blistering disorder. The Tzanck test (or direct smear) is an easy, fast, and inexpensive diagnostic test to verify a clinical cutaneous HSV infection [9]. Sensitivity rates have been reported to be in the range of $73-100 \%$. This rate is inferior to diagnostic tools like PCR and dependent upon doctors' experience. Also, the type and duration of the lesions evaluated are important for the accuracy of the Tzanck test. Optimal lesions are fresh, intact blisters of 1-3 days' duration. If blisters are absent, wet or eroded lesions are preferred to crusted lesions [9]. Our negative Tzanck test could be explained by suboptimal lesions (crusted and eroded blisters).

Immunohistochemical staining, using polyclonal antibodies with cross-reactivity between HSV-1 and HSV-2 cannot differentiate between HSV-1 and HSV-2. In our case, HSV-1 infection is most likely, because of the co-existence of orofacial crustae.

Unfortunately no PCR was performed to confirm HSV-1 infection.

\section{Conclusion}

This case report emphasises the importance of clinical awareness of the occurrence of extensive and atypical mucocutaneous HSV infections in immunocompromised patients. Furthermore, a negative Tzanck test does not rule out the presence of a HSV infection.

Fig. 1. Eroded vesicles and blisters with minimal surrounding erythema on the back.

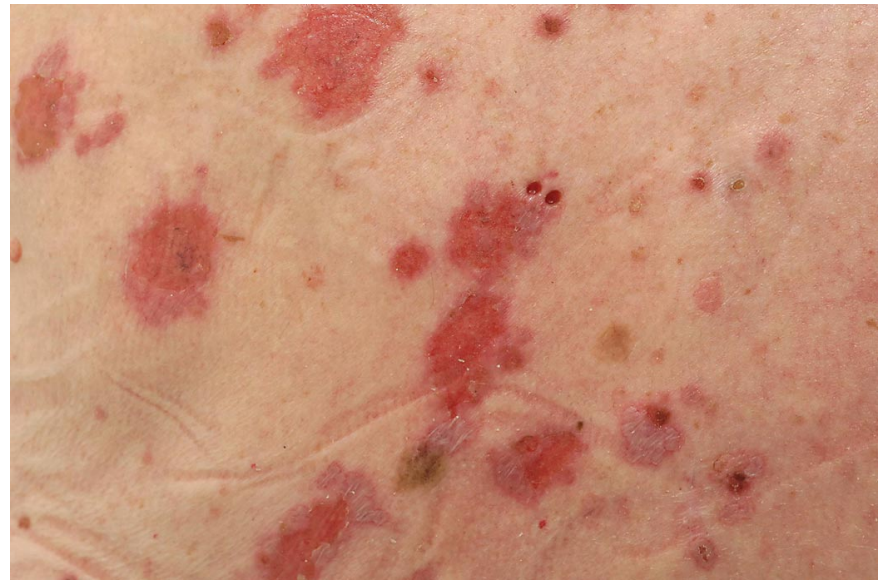




\section{References}

1 Madkan V, Sra K, Brantley J, Carrasco D, Mendoza N, Tyring SK: Human herpes viruses; in Bolognia JL, Jorizzo JL, Rapini RP (eds): Dermatology, ed 2. Philadelphia, Elsevier, 2008, pp 1199-1204.

-2 Whitley RJ, Roizman B: Herpes simplex virus infections. Lancet 2001;357:15131518.

-3 Burgoyne M, Burke W: Atypical herpes simplex infection in patients with acute myelogenous leukaemia recovering from chemotherapy. J Acad Dermatol 1989;20:1125-1127.

4 Johnson JR, Egaas S, Gleaves R, Hackman R, Bowden RA: Hepatitis due to herpes simplex virus in marrow-transplant recipients. Clin Infect Dis 1992;14:38-45.

5 Kusne, S, Schwartz M, Breinig MK, Dummer JS, Lee RE, Selby R, Starzl TE, Simmons RL, Ho M: Herpes simplex virus hepatitis after solid organ transplantation in adults. J Infect Dis 1991;196:1001-1007.

6 6 Taylor RJ, Saul SH, Dowling JN: Primary disseminated herpes simplex infection with fulminant hepatitis following renal transplantation. Arch Int Med 1981;141:1519-1521.

7 Walker DP, Longson M, Lawler W, Mallick NP, Davies JS, Johnson RW: Disseminated herpes simplex virus infection with hepatitis in an adult renal transplant recipient. J Clin Pathol 1981;34:1044-1046.

-8 Herget GW, Riede UN, Schmitt-Graff A, Lübbert M, Neumann-Haefelin D, Köhler G: Generalized herpes simplex infection in an immunocomprised patient - report of a case and review of the literature. Pathol Res Pract 2005;201:123-129.

-9 Ozcan A, Senol M, Saglam H, Seyhan M, Durmaz R, Aktas E, Ozerol IH: Comparison of the Tzanck test and polymerase chain reaction in the diagnosis of cutaneous herpes simplex and varicella zoster virus infections. Int J Dermatol 2007;46:1177-1179. 